\title{
Key determinants of induced abortion in women seeking postabortion care in hospital facilities in Ouagadougou, Burkina Faso
}

This article was published in the following Dove Press journal:

International Journal of Women's Health

29 May 2014

Number of times this article has been viewed

\author{
Patrick GC Ilboudo ${ }^{1-3}$ \\ Serge MA Somda ${ }^{4}$ \\ Johanne Sundby ${ }^{3}$ \\ 'Département de Santé Publique, \\ Unité de Recherche sur les Politiques \\ et Systèmes de Santé, Centre \\ Muraz, Bobo-Dioulasso, Burkina \\ Faso; ${ }^{2}$ Agence de Formation, de \\ Recherche et d'Expertise en Santé \\ pour l'Afrique (AFRICSanté), Bobo- \\ Dioulasso, Burkina Faso; ${ }^{3}$ Department \\ of Community Medicine, University \\ of Oslo, Oslo, Norway; ${ }^{4}$ Département \\ des Maladies Non Transmissibles, \\ Unité de Formation et d'Appui \\ Méthodologique, Centre Muraz, Bobo- \\ Dioulasso, Burkina Faso
}

Correspondence: Patrick GC Ilboudo Département de Santé Publique, Unité de Recherche sur les Politiques et Systèmes de Santé, Centre Muraz, 2054 Avenue Mamadou Konaté, OI BP 390 BoboDioulasso, Burkina Faso

Tel +22620970l 02

Email ipatrickgc@gmail.com
Introduction: Despite the universal recognition of unsafe abortion as a major public health problem, very little research has been conducted to document its precipitating factors in Burkina Faso. Our aim was to investigate the key determinants of induced abortion in a sample of women who sought postabortion care.

Materials and methods: A cross-sectional household survey was carried out from February to September 2012 in Ouagadougou, Burkina Faso. Data of 37 women who had had an induced abortion and 267 women who had had a spontaneous abortion were prospectively collected on sociodemographic characteristics, pregnancy and birth history, abortion experience, including previous abortion experience, and selected clinical information, including the type of abortion. A two-step regression analysis consisting of a univariate and a multivariate logistic regression was run on Stata version 11.2 in order to identify the key determinants of induced abortion.

Results: The findings indicated that $12 \%$ of all abortions were certainly induced. Three key factors were significantly and positively associated with the probability of having an induced abortion: whether the woman reported that her pregnancy was unwanted (odds ratio [OR] $10.45,95 \%$ confidence interval [CI] 3.59-30.41); whether the woman reported was living in a household headed by her parents (OR 6.83, 95\% CI 2.42-19.24); and if the woman reported was divorced or widowed (OR 3.47, 95\% CI 1.08-11.10). On the contrary, being married was protective against induced abortion, with women who reported being married having an $83 \%$ (OR 0.17, CI 0.03-0.89) lower chance of having an induced abortion, even when the pregnancy was unwanted.

Conclusion: This study has identified three major determinants of induced abortion in Ouagadougou, Burkina Faso. Improved targeted programs on family planning counseling, methods of contraception, and availability of contraceptives should be widely promoted.

Keywords: induced abortion, determinants, logistic regression, unwanted pregnancy, crosssectional study

\section{Introduction}

In recent years, the reduction of maternal mortality and morbidity has been a major topic in many international symposia and summits. Consequently, several countries committed themselves towards the achievement of the Millennium Development Goal 5, which aimed at reducing maternal mortality by three-quarters by $2015 .{ }^{1}$ Although improvements have been reported in mothers' survival, the World Health Organization still estimated that many women (287,000 in 2010) continue to die worldwide from various causes related to pregnancy and childbirth. ${ }^{2}$ A large part of these deaths $(66,500)$, which are attributable to unsafe induced abortions, ${ }^{3}$ occur in sub-Saharan countries, ${ }^{4}$ in which abortion laws are mostly restrictive. ${ }^{5}$ 
Several studies have addressed the issue and have analyzed the prerequisites for induced abortions in many countries. They have shown that many women turn to abortion to terminate their unwanted pregnancies, ${ }^{6,7}$ even when laws are prohibitive and methods are unsafe. Studies have also reported that hospital admissions resulting from unsafe abortions were frequent. ${ }^{8-10}$ Moreover, it has been demonstrated that these induced abortions are associated with numerous adverse health problems, such as chronic pelvic inflammatory diseases,${ }^{11}$ mental disorders, ${ }^{12}$ subsequent adverse reproductive outcomes, ${ }^{13}$ and even secondary infertility. ${ }^{14}$

In Burkina Faso, abortion is permitted only in cases of incest, rape, fetal defect, or when the woman's life or physical health is endangered..$^{15,16}$ Because of this, access to safe and legal abortion is difficult to get and women often resort to unsafe procedures, ${ }^{15}$ at great risk to their health and survival. A previous hospital study revealed that up to $30 \%$ of maternal deaths have been the result of unsafe induced abortions. ${ }^{17}$ Additionally, it was estimated that each year, more than 21,800 complications from unsafe induced abortions have been treated in the country's hospital facilities. ${ }^{15}$ However, these data may largely underestimate the magnitude of the phenomenon, as investigations have highlighted that abortion numbers ${ }^{18}$ and related morbidity and mortality ${ }^{15}$ tend to be underreported. ${ }^{18}$

Despite the prevalence of induced abortion, estimated to vary between 25 and 40 per 1,000 women aged 15-49 years annually,,$^{15,19}$ it is likely that the extent of the problem has not been thoroughly studied. Particularly, information on the conditions and key factors that may precipitate induced abortion is lacking. However, knowledge of these factors is critical in designing appropriate strategies aimed at reducing both unwanted pregnancies and unsafe induced abortions. ${ }^{20}$ In Burkina Faso, factors associated with induced abortions have not been studied, in spite of their policy relevance. This study aims at contributing to the literature by investigating the key determinants of induced abortion in a sample of women who resorted to health facilities in Ouagadougou for postabortion care.

\section{Materials and methods Study area}

Burkina Faso, a landlocked country located in the heart of West Africa, has a weak health care system. ${ }^{21}$ The country has a population of 16 million, essentially young and fertile. ${ }^{22}$ The low purchasing power of the population and of women in particular, limits their access to education, clean water, and health care. Maternal mortality is high, with a rate of
300 per 100,000 births. ${ }^{23}$ Contraceptive use is low, with large disparities between poor and rich population groups. ${ }^{24}$ Since 2006, a national subsidy policy for normal deliveries and emergency obstetric care has been active, in order to reduce financial barriers to care and thereby improve access to qualified care. ${ }^{25}$ In spite of this policy, utilization of health care services in Ouagadougou city is still unsatisfactory, with large inequities between poor and rich women.

\section{Study participants and data collection}

In order to explore the key determinants of induced abortion, this paper uses data from a cross-sectional study that investigates the costs associated with abortions in Ouagadougou. Because of the difficulty of recruiting abortion cases in the community, ${ }^{26}$ participants were prospectively recruited from two hospital facilities. These hospital facilities included one referral-level teaching hospital - a top referral hospital in Ouagadougou to which complications from abortion are directed for better care - and one private health clinic, affiliated with the International Planned Parenthood Federation, with long-standing expertise in treating abortions. A total of 307 women with either a spontaneous or induced abortion were sampled for this study. In each facility, an experienced midwife, generally responsible for the manual vacuumaspiration ward, was in charge of identifying women with induced or spontaneous abortions based on clinical definitions. Additional information on the nature of the abortion was also obtained by interviewing the woman. A case was classified as an induced abortion when the clinical ascertainment was confirmed by the woman herself reporting that she had had an induced abortion. All other abortions were classified as possibly spontaneous. This procedure of classifying the cases may have led to some induced abortions being inaccurately classified as spontaneous. ${ }^{3,27}$ Because of this, women were labeled as "certainly induced abortion" and "reportedly spontaneous abortion". Two women did not consent to participate in the study. Another woman was excluded because she did not complete the interview, leaving a sample size of 304.

Data collection took place between February and September 2012. After they were identified by the health staff, the women were directed to two female interviewers who were in charge of establishing contact with them for further investigation. All women who met the eligibility criteria were invited to participate in the study. At discharge, subjects who consented to participate in the study were interviewed at the health facility, at the clinic, or at home. The two qualified female interviewers collected data from all the women who had had an induced or a spontaneous 
abortion, using an interviewer-administered face-to-face questionnaire. Prior to fieldwork, interviewers were given comprehensive training on data collection procedures and extraction of clinical data from medical records. During this training session, anticipated difficulties in filling in the questionnaires were thoroughly discussed in order to minimize errors.

Two structured questionnaires were used for data collection. The main questionnaire that was administered to the women contained a range of questions pertaining to sociodemographic characteristics, pregnancy and birth history, abortion experience, asset ownership and place of residence, and expenditures on abortion and postabortion care, including prereferral costs. The abortion-experience section of the women's questionnaire included questions pertaining to previous abortion experiences and to the type of abortive method used. The women's questionnaire was complemented with a health worker questionnaire, which was intended to extract selected medical information from hospital records. This questionnaire included information related to the gestational age of the pregnancy and the clinical ascertainment of the type of abortion.

\section{Dependent variable studied}

The dependent variable was the type of abortion, a dummy variable set to 1 when the pregnancy termination was reported as induced or 0 when alleged to be a spontaneous abortion.

\section{Independent variables analyzed}

The empirical literature on factors associated with abortion showed that educated women, ${ }^{28-32}$ young women, ${ }^{28-30,33-36}$ unmarried women, ${ }^{28,30,34,37,38}$ women who had had previous experiences of abortion, ${ }^{31,34,39}$ women who had living children, ${ }^{29,33,34}$ and women who did not want the pregnancy ${ }^{28,39-41}$ were more likely to have an induced abortion. Therefore, such variables as age, education, marital status, number of children, desire for pregnancy, and previous experience of abortion were considered independent variables. Researchers have also demonstrated that women who were experiencing their first pregnancy in life, ${ }^{30} \mathrm{Christian}$ women (compared to Muslim women), ${ }^{33,36,39}$ and women who did not use contraceptives ${ }^{40}$ were also more likely to have an induced abortion. We therefore also considered the number of pregnancies, the use of contraceptives, and the women's religion as explanatory variables. Finally, we included the status of the householdchief (whether the household is headed by the woman, the husband, or by the woman's parents) in the analysis of abortion determinants.

\section{Statistical analysis}

A descriptive analysis was undertaken in order to understand the distribution of induced and spontaneous abortions relative to each independent variable. Chi-squared tests were used to test for significant differences between the groups of women. To identify the key determinants associated with induced abortion for women seeking postabortion care in hospitals in Ouagadougou, a two-step analysis consisting of one univariate and one multivariate logistic regression was carried out. The univariate logistic regression was run to determine the association between each of the independent variables and the dependent variable. All the variables that were associated with induced abortion in the univariate logistic regression with a level of significance of 0.05 and $95 \%$ confidence were subsequently analyzed in a stepwise multivariate logistic regression. The multivariate regression permitted adjustment among variables and the determination of possible confounding factors. To identify the key factors associated with induced abortion, a downward procedure that minimizes the number of variables while maximizing the accuracy of the model was followed ${ }^{42}$ All analyses were conducted on Stata version 11.2 (StataCorp, College Station, TX, USA).

\section{Results}

\section{Population characteristics}

Table 1 summarizes the distribution of the studied variables. Women who had had an induced abortion constituted $12 \%$ of the sample; $61 \%$ of the women were married, and $63 \%$ were under 30 years old. Education (primary to university level) was not common in our sample, with only $33 \%$ of the women being formally educated. Among the women, 28\% declared that their pregnancies were unwanted, and $17 \%$ had had a previous experience of abortion, while $29 \%$ were on their first pregnancy, $77 \%$ were living in households headed by their parents, and up to $80 \%$ were not using any form of contraception.

\section{Estimation of associations}

Table 2 shows associations of induced abortion with the analyzed variables. Induced abortions tended to be more prevalent in the educated (16\%), under 30 years old (17\%), single or never married (24\%), and widowed or divorced (57\%) women, compared to the uneducated, the married, and women over the age of 30 years. We also found that induced abortion was more prevalent in women who had had a previous experience of abortion (68\%), in women who did not want the pregnancy (37\%), in women who were 
Table I Study population and variables analyzed $(n=304)$

\begin{tabular}{ll}
\hline Variables & Respondents (\%) \\
\hline Type of abortion & \\
$\quad$ Certainly induced & $37(12 \%)$ \\
Allegedly spontaneous & $267(88 \%)$ \\
Age & \\
$\quad<30$ years & $191(63 \%)$ \\
$\geq 30$ years & $113(37 \%)$ \\
Education & \\
Formal education & $99(33 \%)$ \\
Not educated & $205(67 \%)$ \\
Marital status & \\
Married & $186(61 \%)$ \\
Single/never married & $97(32 \%)$ \\
Widowed/divorced & $21(7 \%)$ \\
Previous abortion & \\
Yes & $53(17 \%)$ \\
No & $251(83 \%)$ \\
Number of living children & \\
0 & $191(63 \%)$ \\
$\geq I$ & $113(37 \%)$ \\
Pregnancy & \\
Wanted & $220(72 \%)$ \\
Unwanted & $84(28 \%)$ \\
Number of pregnancies & \\
I & $88(29 \%)$ \\
Religion & $216(71 \%)$ \\
Christian & \\
Muslim & $115(38 \%)$ \\
Woad of household & $189(62 \%)$ \\
Yes orents & \\
No & $70(23 \%)$ \\
\hline
\end{tabular}

experiencing their first pregnancy (26\%), in those with living children (24\%), in women under parents' guardianship (41\%), and in Christians (20\%). The univariate analysis further showed that all the considered variables, except the use of contraceptives, were associated with induced abortion. Therefore, being educated, aged less than 30 years, widowed or divorced, and in a household headed by parents all tended to increase the odds of having an induced abortion. We also found that having a previous experience of abortion or having living children, being on the first pregnancy, or the pregnancy being unwanted increased the odds of having an induced abortion. On the contrary, being married or a Muslim tended to decrease the odds of having an induced abortion by $97 \%$ and $68 \%$, relative to being single or a Christian, respectively.

Moreover, in the multivariate analysis, we found that three key factors, comprising the desire for pregnancy, living in a
Table 2 Association between induced abortion and independent variables

\begin{tabular}{|c|c|c|c|}
\hline Variables & $\begin{array}{l}\text { Induced } \\
\text { abortion (\%) }\end{array}$ & $\begin{array}{l}\text { Unadjusted OR } \\
(95 \% \mathrm{Cl})\end{array}$ & $P$-value \\
\hline \multicolumn{4}{|l|}{ Age } \\
\hline$<30$ years & $33(17 \%)$ & $5.69(1.98-16.53)$ & 0.001 \\
\hline$\geq 30$ years & $4(4 \%)$ & 1 & \\
\hline \multicolumn{4}{|l|}{ Education } \\
\hline Educated & $33(16 \%)$ & $4.56(1.57-13.25)$ & 0.005 \\
\hline Not educated & $4(4 \%)$ & 1 & \\
\hline \multicolumn{4}{|l|}{ Marital status } \\
\hline Married & $2(1 \%)$ & $0.03(0.01-0.15)$ & $<0.001$ \\
\hline $\begin{array}{l}\text { Single/never } \\
\text { married }\end{array}$ & $23(24 \%)$ & 1 & \\
\hline $\begin{array}{l}\text { Widowed/ } \\
\text { divorced }\end{array}$ & $12(57 \%)$ & $4.29(1.61-11.46)$ & 0.004 \\
\hline \multicolumn{4}{|l|}{ Previous abortion } \\
\hline Yes & $36(68 \%)$ & 529.41 (68.37-4099.39) & $<0.001$ \\
\hline No & I (l\%) & 1 & \\
\hline \multicolumn{4}{|c|}{ Number of living children } \\
\hline 0 & $10(5 \%)$ & 1 & \\
\hline$\geq 1$ & $27(24 \%)$ & $5.68(2.63-12.27)$ & $<0.001$ \\
\hline \multicolumn{4}{|l|}{ Pregnancy } \\
\hline Wanted & $6(3 \%)$ & 1 & \\
\hline Unwanted & 31 (37\%) & $20.86(8.28-52.58)$ & $<0.001$ \\
\hline \multicolumn{4}{|c|}{ Number of pregnancies } \\
\hline I & $23(26 \%)$ & $5.11(2.48-10.50)$ & $<0.001$ \\
\hline$\geq 1$ & $14(6 \%)$ & 1 & \\
\hline \multicolumn{4}{|l|}{ Religion } \\
\hline Christian & $23(20 \%)$ & 1 & \\
\hline Muslim & $14(7 \%)$ & $0.32(0.16-0.65)$ & 0.002 \\
\hline \multicolumn{4}{|l|}{ Head of household } \\
\hline Woman/husband & $8(3 \%)$ & 1 & \\
\hline Parents & $29(41 \%)$ & $19.98(8.54-46.77)$ & $<0.001$ \\
\hline \multicolumn{4}{|l|}{ Use of contraceptives } \\
\hline Yes & $9(15 \%)$ & 1 & \\
\hline No & $28(12 \%)$ & $0.75(0.33-1.69)$ & 0.491 \\
\hline
\end{tabular}

Abbreviations: $\mathrm{OR}$, odds ratio; $\mathrm{Cl}$, confidence interval.

household headed by the woman's parents, and the woman's marital status, were all associated with induced abortion (Table 3). The effect of the desire for pregnancy was the most important, with the odds of having an induced abortion being ten times higher for women who did not want the pregnancy compared to those who did want it (odds ratio [OR] 10.45, 95\% confidence interval [CI] 3.59-30.41). Further, the odds of having an induced abortion were seven times higher for women living in households headed by their parents (OR 6.83, 95\% CI 2.42-19.24). The odds of having an induced abortion also increased by three times for divorced or widowed women (OR 3.47, 95\% CI 1.08-11.10) compared to single or never-married women. On the contrary, married women were $83 \%$ less likely to have an induced abortion, even when the pregnancy was not desired (OR 0.17, 
Table 3 Key determinants associated with induced abortion

\begin{tabular}{|c|c|c|}
\hline \multirow[t]{2}{*}{ Variables } & \multicolumn{2}{|l|}{ Multivariate analysis } \\
\hline & Adjusted OR (95\% Cl) & $P$-value \\
\hline \multicolumn{3}{|l|}{ Marital status } \\
\hline Married & $0.17(0.03-0.89)$ & 0.036 \\
\hline Single/never married & 1.00 & \\
\hline Widowed/divorced & $3.47(1.08-11.10)$ & 0.036 \\
\hline \multicolumn{3}{|l|}{ Pregnancy } \\
\hline Wanted & 1.00 & \\
\hline Unwanted & $10.45(3.59-30.41)$ & $<0.001$ \\
\hline \multicolumn{3}{|l|}{ Head of household } \\
\hline Woman/husband & 1.00 & \\
\hline Parents & $6.83(2.42-19.24)$ & $<0.001$ \\
\hline Model $\chi^{2}$ & 111.10 & $<0.0001$ \\
\hline Pseudo- $R^{2}$ & 0.4932 & \\
\hline $\mathrm{n}$ & 304 & \\
\hline
\end{tabular}

Abbreviations: $\mathrm{OR}$, odds ratio; $\mathrm{Cl}$, confidence interval.

95\% CI 0.03-0.89), compared to single or never-married women. Finally, we found that age, education, previous experience of abortion, number of living children, number of pregnancies, and religion had no significant effect on having an induced abortion.

\section{Discussion}

This study reports that $12 \%$ of the women who received postabortion care in hospitals had had induced abortions. This proportion was comparable to those found by Majlessi et al $(2008)^{41}$ in Iran and Lema et al (1996) ${ }^{28}$ in Kenya, who found that $15.7 \%$ and $12 \%$, respectively, of the women they interviewed had had confirmed induced abortions. Furthermore, the distribution of the cases indicated that induced abortion is mostly prevalent among young, educated, unmarried women. Several other studies also reported the same findings. ${ }^{28-31,33,34,36-38}$ It was also prevalent among women with previous abortion experience, among those on their first pregnancy, those who did not want the pregnancy, those with living children, and Christians, as well as among those living with their parents. Again, these findings were consistent with those from previous studies. ${ }^{30,33,36,40}$

Among the women who sought postabortion care, three key factors - the desire for pregnancy (whether wanted or not), the status of the head-of-household (whether the household was headed by the woman's parents or by either the woman herself or her partner/husband), and the woman's marital status - were positively associated with induced abortion. Women with unwanted pregnancies were more likely to have an induced abortion. This finding was consistent with previous study findings. ${ }^{28,39-41}$ Unavailable, unused, or failed contraceptives, as well as males' involvement may explain the decision to abort. For example, $80 \%$ of the women in this study were not using contraceptives. This high level of unmet need for contraception was consistent with previous research findings in Burkina Faso ${ }^{24}$ and in other sub-Saharan regions. ${ }^{43}$ Since safe and legal abortions are difficult to get in Burkina Faso, the only "choice" left to these women is to go for an illegal abortion whenever they feel that they cannot bear their pregnancies.

Induced abortion was also associated with the status of the head-of-household. This result corroborates that of a previous study that highlighted the parents' role in abortionseeking behavior. ${ }^{36}$ Despite the country's pronatalist mentality, sexuality and pregnancy outside marriage are seen as dishonorable by families, who ultimately may disown daughters who fail to stay virgins until marriage. Because of fear of disownment, many women, particularly unmarried women living with their parents, may be more likely to have an induced abortion to end an unwanted pregnancy. Such practices are prevalent in many African societies, in which cultural beliefs make it a point of honor to remain chaste until marriage. ${ }^{44}$

Moreover, induced abortion was associated with women's marital status. Compared to single or never-married women, divorced or widowed women were more likely to resort to induced abortion. On the contrary, married women were less likely to have an induced abortion. This finding is consistent with several other studies that highlighted the role of marital status in abortion decision making. $28,30,34,37,38$ The desire not to have any more children may explain the increased likelihood of induced abortion in divorced or widowed women. Additionally, because widowed women are still considered as belonging to the deceased husband's family, a new pregnancy may be subject to censure and even the isolation of the woman, particularly if the husband's death is still fresh. This may explain why ultimately some widowed women resort to abortion.

We did not find any significant associations between induced abortion and age, education, or the use of contraceptives in the multivariate logistic regression, while various studies have highlighted the critical role of these variables. ${ }^{28-31,33,36,37,40,45,46}$ This may be attributable to the relatively small sample size. In addition, the multivariate modeling may have also adjusted effects between independent variables, eventually removing some correlated variables. This may also explain the failure to find associations between induced abortion and previous abortions, the number of living children, number of pregnancies, and religion. 


\section{Limitations and strengths}

This study has limitations. The survey was primarily conducted with the aim of estimating the costs associated with abortions to households and not specifically to explore the determinants of induced abortion. Because of this, some possible important variables, such as data on the availability of contraceptives or the women's sexual practices, are missing. This study was hospital-based. Its findings may not be generalizable to the whole population of women who have had an induced abortion, as many of them may not present to hospitals for postabortion care.

Moreover, the study failed to capture information on the male responsible for the pregnancy. They may be a key factor in abortion decision making, considering the roles that men may play as supporters, ${ }^{47,48}$ instigators, facilitators, collaborators, or advisors. ${ }^{48}$ Unfortunately, the information we collected that was available on men was exclusively that of the official partner or husband of the women. Analyzing these data may have led to additional biases: firstly, because information on single women's partners was missing, and secondly because the official partner or husband may not be the father of the pregnancy, as some women may have more than one sexual partner.

Therefore, other possibly important variables, such as the number of sexual partners of the woman, may be missing. Furthermore, the face-to-face interview we conducted with the women may have led to classification biases, as some women who had had an induced abortion may have intentionally reported having had spontaneous abortions..$^{27}$ This may have consequences for the findings of the study in the sense that misclassification of the cases will decrease the difference in size between the groups of women and therefore affect the odds ratio. We also think that a selection bias may have affected the results. Some women, particularly the most educated and wealthy, may have sought care in high-standard private clinics rather than the two health facilities in which women were recruited. This may also have contributed to distorting the findings.

Nevertheless, this study has strengths. The comparison group we used was appropriate for the analysis. Because a spontaneous abortion may happen to any woman, irrespective of her level of education, wealth, age, etc, it is likely that women falling into this group may be more representative of pregnant women. Moreover, this study is the first study to examine the key determinants of induced abortion in Burkina Faso. Its findings may therefore be helpful in the fight against induced abortion and its consequences. Finally, it can help in designing a larger, population-based study of the determinants of induced abortions in the whole of Burkina Faso.

\section{Conclusion}

This study showed a positive association between induced abortion and unintended pregnancy. In Burkina Faso, the restrictive abortion law does not prevent women from practicing abortion in cases of unplanned and unwanted pregnancy. This is the case for single women, for women who are divorced or widowed, and women living with their parents, for whom the risk associated with induced abortion is high, especially when the pregnancy is unwanted. This study importantly points to the fact that many women who are sexually active and who do not want to be pregnant do not use any contraception. We believe that improved provision of family planning counseling and methods of contraception, and better availability of contraceptives, may reduce the prevalence of unsafe abortions.

\section{Acknowledgments}

We would like to thank Gérard Ilboudo for his help, and Mireille Ilboudo and Amélie Zongo for their invaluable assistance during fieldwork. Special thanks to Henri Somé for his priceless assistance with data processing and cleaning. We are also grateful to Souleymane Kékélé, Gaston Soulama, and Yassiya Ouédraogo for data entry. We finally thank all the women who accepted to disclose their cases. This work was supported by the Research Council of Norway's ECONPOP program (199730/H30).

\section{Author contributions}

All authors (except SMAS) participated in the design of the data collection instruments. The fieldwork was coordinated and supervised by PGCI. SMAS and PGCI analyzed the quantitative data. PGCI wrote the first draft of the paper, with specific inputs from SMAS and JS, who revised all subsequent drafts. All authors contributed to the interpretation of the findings and to the writing.

\section{Disclosure}

The authors report no conflicts of interest in this work.

\section{References}

1. United Nations. United Nations Millennium Development Declaration. New York: UN; 2000.

2. World Health Organization. Trends in Maternal Mortality: 1990 to 2010. WHO, UNICEF, UNFPA and the World Bank Estimates. Geneva: WHO; 2012.

3. Rasch V. Unsafe abortion and postabortion care - an overview. Acta Obstet Gynecol Scand. 2011;90(7):692-700.

4. Grimes DA, Benson J, Singh S, et al. Unsafe abortion: the preventable pandemic. Lancet. 2006;368(9550):1908-1919.

5. Hord C, Wolf M. Breaking the cycle of unsafe abortion in Africa. Afr J Reprod Health. 2004;8(1):29-36. 
6. Singh S, Wulf D, Hussain R, Bankole A, Sedgh G. Abortion Worldwide: A Decade of Uneven Progress. New York: Guttmacher Institute; 2009.

7. Shah I, Ahman E. Unsafe abortion: global and regional incidence, trends, consequences, and challenges. J Obstet Gynaecol Can. 2009;31(12): 1149-1158.

8. Singh S. Hospital admissions resulting from unsafe abortion: estimates from 13 developing countries. Lancet. 2006;368(9550):1887-1892.

9. Abiodun OM, Balogun OR, Adeleke NA, Farinloye EO. Complications of unsafe abortion in South West Nigeria: a review of 96 cases. Afr $J$ Med Med Sci. 2013;42(1):111-115.

10. Berer M. Hospital admission for complications of unsafe abortion. Lancet. 2006;368(9550):1848-1849.

11. Lapido OC. Preventing and managing complications of induced abortions in Third World countries. Suppl Int J Gynecol Obstet. 1989;3:21-28.

12. Mota NP, Burnett M, Sareen J. Associations between abortion, mental disorders, and suicidal behaviour in a nationally representative sample. Can J Psychiatry. 2010;55(4):239-247.

13. Bhattacharya S, Lowit A, Raja EA, Lee AJ, Mahmood T, Templeton A. Reproductive outcomes following induced abortion: a national registerbased cohort study in Scotland. BMJ Open. 2012;2(4).

14. Koster W. Linking two opposites of pregnancy loss: Induced abortion and infertility in Yoruba society, Nigeria. Soc Sci Med. 2010;71(10): 1788-1795.

15. Sedgh G, Rossier C, Kaboré I, Bankole A, Mikulich M. Estimating abortion Incidence in Burkina Faso using two methodologies. Stud Fam Plann. 2011;42(3):147-154.

16. Center for Reproductive Rights. Les faits: lois relatives à l'avortement à travers le monde. 1999. Available from: http://reproductiverights.org/ $\mathrm{fr} /$ document/les-faits-lois-relatives-\%C3\%A0-lavortement-\%C3\%A0travers-le-monde. Accessed March 29, 2014.

17. Lankoande J, Ouedraogo CM, Ouedraogo A, et al. La mortalité maternelle chez les adolescentes au CHU de Ouagadougou [Maternal mortality in adolescents at the university hospital of Ouagadougou]. Rev Med Brux. 1999;20(2):87-89. French.

18. Ahman E, Dolea C, Shah I. The Global Burden of Unsafe Abortion in the Year 2000. Geneva: WHO; 2005.

19. Rossier C, Guiella G, Ouedraogo A, Thieba B. Estimating clandestine abortion with the confidants method - results from Ouagadougou, Burkina Faso. Soc Sci Med. 2006;62(1):254-266.

20. Fedorova GV, Baniushevich IA. [Factors impacting abortion prevalence] Probl Sotsialnoi Gig Zdravookhranenniiai Istor Med. 2005(6):19-23. Russian.

21. Ridde V, Meessen B, Kouanda S. L'abolition sélective du paiement direct en Afrique subsaharienne: une opportunité pour le renforcement des systèmes de santé? [Selective free health care in sub-Saharan Africa: an opportunity for strengthening health systems?]. Sante Publique. Jan-Feb 2011;23(1):61-67. French.

22. United Nations. World Population Prospects: The 2012 Revision. New York: UN; 2013.

23. World Health Organization. World Health Statistics 2012: HealthRelated Millennium Development Goals Part I. Geneva, WHO; 2012.

24. Vlassoff M, Sundaram A, Bankole A, Remez L, Belemsaga-Yugbare D. Benefits of meeting women's contraceptive needs in Burkina Faso. Issues Brief (Alan Guttmacher Inst). 2011;(1):1-33.

25. Ministère de la Santé Burkina Faso. Stratégie nationale de subvention des accouchements et des soins obstétricaux et néonatals d'urgence au Burkina Faso [Ministry of Health Burkina Faso. National Strategy subsidy for deliveries and emergency obstetric and neonatal care in Burkina Faso]. Ouagadougou, Burkina Faso; 2006. French.

26. Osis MJ, Hardy E, Faundes A, Rodrigues T. Dificuldades para obter informações da população de mulheres sobre aborto ilegal [Difficulties encountered in gathering information on illegal abortion in the population of women]. Rev Saude Publica. 1996;30(5):444-451. Portuguese.
27. Rasch V, Muhammad H, Urassa E, Bergstrom S. Self-reports of induced abortion: an empathetic setting can improve the quality of data. $\mathrm{Am} J$ Public Health. 2000;90(7):1141-1144.

28. Lema VM, Rogo KO, Kamau RK. Induced abortion in Kenya: its determinants and associated factors. East Afr Med J. 1996;73(3): 164-168.

29. Guilbert E, Marcoux S, Rioux JE. Factors associated with the obtaining of a second-trimester induced abortion. Can J Public Health. 1994;85(6):402-406.

30. Ibrahim IA, Onwudiegwu U. Sociodemographic determinants of complicated unsafe abortions in a semi-urban Nigerian town: a four-year review. West Indian Med J. 2012;61(2):163-167.

31. Figueroa-Lara A, Aracena-Genao B, Reyes-Morales H, LamadridFigueroa H. [Factors associated with the seeking of legal induced abortion services in Mexico City in 2010]. Salud Publica Mex. 2012;54(4):401-409. Spanish.

32. Ranji A. Induced abortion in Iran: prevalence, reasons, and consequences. J Midwifery Womens Health. 2012;57(5):482-488.

33. Fonseca W, Misago C, Correia LL, Parente JA, Oliveira FC. Determinantes do aborto provocado entre mulheres admitidas em hospitais em localidade da região Nordeste do Brasil [Determinants of induced abortion among poor women admitted to hospitals in a locality of northeastern Brazil]. Rev Saude Publica. 1996;30(1):13-18. Portuguese.

34. Misago C, Fonseca W, Correia L, Fernandes LM, Campbell O. Determinants of abortion among women admitted to hospitals in Fortaleza, North Eastern Brazil. Int J Epidemiol. 1998;27(5): 833-839.

35. Mote CV, Otupiri E, Hindin MJ. Factors associated with induced abortion among women in Hohoe, Ghana. Afr Reprod Health. 2010; 14(4 Spec no):110-116.

36. Okereke CI. Assessing the prevalence and determinants of adolescents' unintended pregnancy and induced abortion in Owerri, Nigeria. J Biosoc Sci. 2010;42(5):619-632.

37. Adetoro OO, Babarinsa AB, Sotiloye OS. Socio-cultural factors in adolescent septic illicit abortions in Ilorin, Nigeria. Afr J Med Med Sci. 1991;20(2):149-153.

38. Mitsunaga TM, Larsen UM, Okonofua FE. Risk factors for complications of induced abortions in Nigeria. $J$ Womens Health (Larchmt). 2005;14(6):515-528.

39. Wu S, Tian L, Xu F. Induced abortion and relevant factors among women seeking abortion in Nanjing, China. Gynecol Oobstet Invest. 2011;71(2):87-92.

40. Korejo R, Noorani KJ, Bhutta S. Sociocultural determinants of induced abortion. J Coll Physicians Surg Pak. 2003;13(5):260-262.

41. Majlessi F, Forooshani AR, Shariat M. Prevalence of induced abortion and associated complications in women attending hospitals in Isfahan. East Mediterr Health J. 2008;14(1):103-109.

42. Hosmer DW, Lemeshow S. Applied Logistic Regression. 2nd ed. Hoboken (NJ): John Wiley \& Sons; 2000.

43. Hubacher D, Mavranezouli I, McGinn E. Unintended pregnancy in sub-Saharan Africa: magnitude of the problem and potential role of contraceptive implants to alleviate it. Contraception. 2008;78(1): 73-78.

44. Rossier C. Abortion: an open secret? Abortion and social network involvement in Burkina Faso. Reprod Health Matters. 2007;15(30): $230-238$.

45. Gessessew A. Abortion and unwanted pregnancy in Adigrat Zonal Hospital, Tigray, north Ethiopia. Afr J Reprod Health. 2010;14(3): $183-188$.

46. Xu JS, Huang YM, Cheng LN. [Factors in relation to repeated abortions among unmarried young people in Shanghai]. Zhonghua Liu Xing Bing Xue Za Zhi. 2007;28(8):742-745. Chinese.

47. Dudgeon RM, Inhorn CM. Men's influences on women's reproductive health: medical anthropological perspectives. Soc Sci Med. 2004;59(7):1379-1395.

48. Nyanzi S, Nyanzi B, Bessie K. "Abortion? That's for women!" Narratives and experiences of commercial motorbike riders in southwestern Uganda. Afr J Reprod Health. 2005;9(1):142-161. 
International Journal of Women's Health

Dovepress

\section{Publish your work in this journal}

The International Journal of Women's Health is an international, peerreviewed open-access journal publishing original research, reports, editorials, reviews and commentaries on all aspects of women's healthcare including gynecology, obstetrics, and breast cancer. The manuscript management system is completely online and includes

a very quick and fair peer-review system, which is all easy to use. Visit http://www.dovepress.com/testimonials.php to read real quotes from published authors.

Submit your manuscript here: http://www.dovepress.com/international-journal-of-womens-health-journal 